\title{
Islet inflammation and ductal proliferation may be linked to increased pancreatitis risk in type 2 diabetes
}

\author{
Belinda Schludi, ${ }^{1}$ Abu Saleh Md Moin, ${ }^{1}$ Chiara Montemurro, ${ }^{1}$ Tatyana Gurlo, ${ }^{1}$ \\ Aleksey V. Matveyenko, ${ }^{1}$ David Kirakossian, ${ }^{1}$ David W. Dawson, ${ }^{2,3}$ Sarah M. Dry, ${ }^{2,3}$ \\ Peter C. Butler, ${ }^{1,3}$ and Alexandra E. Butler ${ }^{1}$ \\ 'Larry L. Hillblom Islet Research Center, ${ }^{2}$ Department of Pathology and Laboratory Medicine, ${ }^{3}$ Jonsson Comprehensive \\ Cancer Center, UCLA, David Geffen School of Medicine, Los Angeles, California, USA.
}

\begin{abstract}
Pancreatitis is more frequent in type 2 diabetes mellitus (T2DM), although the underlying cause is unknown. We tested the hypothesis that ongoing $\beta$ cell stress and apoptosis in T2DM induces ductal tree proliferation, particularly the pancreatic duct gland (PDC) compartment, and thus potentially obstructs exocrine outflow, a well-established cause of pancreatitis. PDG replication was increased 2-fold in human pancreas from individuals with T2DM, and was associated with increased pancreatic intraepithelial neoplasia (PanIN), lesions associated with pancreatic inflammation and with the potential to obstruct pancreatic outflow. Increased PDG replication in the prediabetic human-IAPP-transgenic (HIP) rat model of T2DM was concordant with increased $\beta$ cell stress but preceded metabolic derangement. Moreover, the most abundantly expressed chemokines released by the islets in response to $\beta$ cell stress in T2DM, CXCL1, -4 , and -10 , induced proliferation in human pancreatic ductal epithelium. Also, the diabetes medications reported as potential modifiers for the risk of pancreatitis in T2DM modulated PDC proliferation accordingly. We conclude that chronic stimulation and proliferation of the PDC compartment in response to islet inflammation in T2DM is a potentially novel mechanism that serves as a link to the increased risk for pancreatitis in T2DM and may potentially be modified by currently available diabetes therapy.
\end{abstract}

Conflict of interest: The authors have declared that no conflict of interest exists.

Submitted: December 13, 2016

Accepted: May 23, 2017

Published: July 6, 2017

Reference information: JCI Insight. 2017;2(13):e92282. https://doi.org/10.1172/jci. insight. 92282

\section{Introduction}

The incidence of both acute pancreatitis and chronic pancreatitis are increased in type 2 diabetes mellitus (T2DM) (1-4), although the underlying mechanisms for this association are not resolved. A well-recognized risk factor for pancreatitis is delay in passage of exocrine secretions through the ductal tree, for example due to obstruction by an impacted ductal stone or intraductal papillary mucinous neoplasia (IPMN) (5, 6). We previously documented an increase in replication in the pancreatic ductal tree in T2DM compared with BMI-matched nondiabetic controls (7). Recently, the pancreatic duct gland (PDG) compartment has been proposed as a pancreatic stem cell niche that expands through increased proliferation in response to induced pancreatic inflammation, purportedly to regenerate pancreatic duct epithelium $(8,9)$.

The islet in T2DM is characterized by chronic inflammation and a low frequency of ongoing $\beta$ cell apoptosis (10). Proinflammatory cytokines and chemokines likely play a significant role in the pathogenesis of T2DM, and several, including chemokine (C-X-C motif) ligand 1 (CXCL1) and 10 (CXCL10), are increased in the circulation of patients with T2DM (11-13). In mice, proinflammatory chemokines have been shown to directly affect islet function (14), are increased in the circulation with the onset of T2DM, and are produced by the islets under conditions of stress (15), evidence for their role in the pathogenesis of T2DM.

We posed the question, does the longstanding low-grade inflammation in the islet in T2DM potentially serve to induce increased proliferation of the PDG compartment? If so, given that the ductal epithelial cells thus produced would presumably not replace lost duct cells, chronically stimulated production of ductal epithelium by the PDG compartment might result in intraductal pancreatic intraepithelial neoplasia-like (PanIN-like) epithelial projections and hinder exocrine secretion outflow.

In support of this potential model, we establish here that PanIN lesions are more frequent and PDG cell replication is increased in human pancreas from individuals with T2DM compared with body mass- and 
age-matched controls. Alternatively, PDG proliferation in T2DM could be promoted by metabolic changes such as hyperglycemia or hyperinsulinemia consequent upon insulin resistance and/or insulin therapy in T2DM (16). In order to address this, we studied the PDG compartment in the human-IAPP-transgenic (HIP) rat model of T2DM (17). This model is characterized by increased $\beta$ cell apoptosis and $\beta$ cell stress resulting from the formation of toxic intracellular islet amyloid polypeptide (IAPP) oligomers, reproducing the islet phenotype in humans with T2DM (18). This $\beta$ cell inflammatory phenotype in HIP rats precedes diabetes onset, permitting distinction between the potential role of chemokines arising from islet inflammation and the metabolic consequences of diabetes. To further probe the potential link between islet inflammation in T2DM and ductal epithelia, we also evaluated the proliferative actions of candidate chemokines arising from $\beta$ cell inflammation in T2DM on human pancreatic ductal epithelial (HPDE) cells in vitro. Given the potential actions of the glucagon-like peptide-1-based (GLP-1-based) diabetes medications and metformin therapy on the exocrine pancreas in T2DM (19-21), we also evaluated the actions of these drugs on PDG cell replication in the HIP rat model of T2DM.

The results of these studies support the overall hypothesis that chemokine signaling arising from stressed $\beta$ cells in T2DM may induce sustained proliferation of the PDG compartment, potentially explaining the increased intraductal epithelial PanIN-like projections also noted in T2DM. Of interest, administration of metformin suppressed and GLP-1-mimetic therapy amplified the increased proliferation in PDGs in the HIP rat model (22), consistent with some reports of decreased versus increased pancreatitis in patients with T2DM treated with these drugs $(23,24)$. Collectively, these studies offer a potential link between chronic islet inflammation characteristic of T2DM and the, as yet, unexplained association of increased pancreatitis.

\section{Results}

Frequency of PanINs in diabetes. Low-grade PanIN lesions were more commonly detected $(P<0.05)$ in T2DM (Figure 1) than nondiabetic (ND) controls (Supplemental Figure 1; supplemental material available online with this article; https://doi.org/10.1172/jci.insight.92282DS1). No high-grade PanIN lesions were detected. There was no relationship between the frequency of PanINs and BMI in either the T2DM or the ND control group (Figure $1 \mathrm{~F}$ ). There was also no relationship between age of individuals and extent of PanINs and, not surprisingly because of small numbers in each subgroup, there was no statistical difference between drug treatment and PanINs detected in the T2DM cases. In addition, more T2DM donors had reactive ductal changes and foci of IPMN present ( 5 donors) and the lesions were more extensive ( 8 regions) than in the ND donors (3 donors, 3 regions affected).

Since recent evidence suggests PanIN lesions may be derived from activated PDGs $(8,25)$, we sought to characterize the anatomy of the PDG compartment in humans with T2DM compared with ND controls.

$P D G$ replication in human pancreata. PDGs were readily identified as coiled invaginations composed of columnar epithelium arising from interlobular ducts within the mesenchyme surrounding those ducts in sections of the head, body, and tail of the pancreas in all human pancreata studied (Figure 2). PDG cell replication was 2-fold increased in the PDG compartment in T2DM compared with ND controls $(2.0 \% \pm$ $0.4 \%$ vs. $0.8 \% \pm 0.1 \%, P<0.01, \mathrm{~T} 2 \mathrm{DM}$ vs. ND) (Figure 2, C, D, and F). Replication of interlobular duct epithelium was also increased in T2DM (interlobular duct: $2.0 \% \pm 0.4 \%$ vs. $0.8 \% \pm 0.1 \%, P<0.01$, T2DM vs. ND) (Figure $2 \mathrm{~F}$ ). There was no difference between groups in replication of intralobular duct cells (intralobular duct: $0.8 \% \pm 0.1 \%$ vs. $0.7 \% \pm 0.1 \%, P=$ not significant [ns], T2DM vs. ND).

In pancreatic sections from 5 of the 14 individuals with T2DM, it was apparent that PDG cell replication was markedly increased compared with ND controls, whereas in the pancreatic sections of the other 9 T2DM donors the frequency of Ki67-positive PDG cells was comparable to that in ND controls. To probe the potential difference between these groups, T2DM with high PDG replication and T2DM with normal PDG replication, we subdivided the T2DM donors into those with a mean percentage PDG positive for Ki67 of $2.5 \%$ or higher (range $2.6 \%$ to $8.1 \%$ ) and those with a mean percentage PDG positive for Ki67 less than $2.5 \%$ (range $0.0 \%$ to $2.3 \%$ ). This cutoff value was chosen as the mean Ki67-positive PDG percentage value in the normal PDG Ki67-positive T2DM donor group was then matched that of the ND donor group $(0.7 \pm 0.3$ vs. $0.8 \pm 0.2 \%$, T2DM vs. ND, $P=\mathrm{ns})$.

To investigate the potential mechanisms accounting for the difference between the high versus normal PDG cell replication groups, we next considered both technical and patient characteristics, because of potential influences of the preterminal clinical condition (26). With respect to the former, order effect 

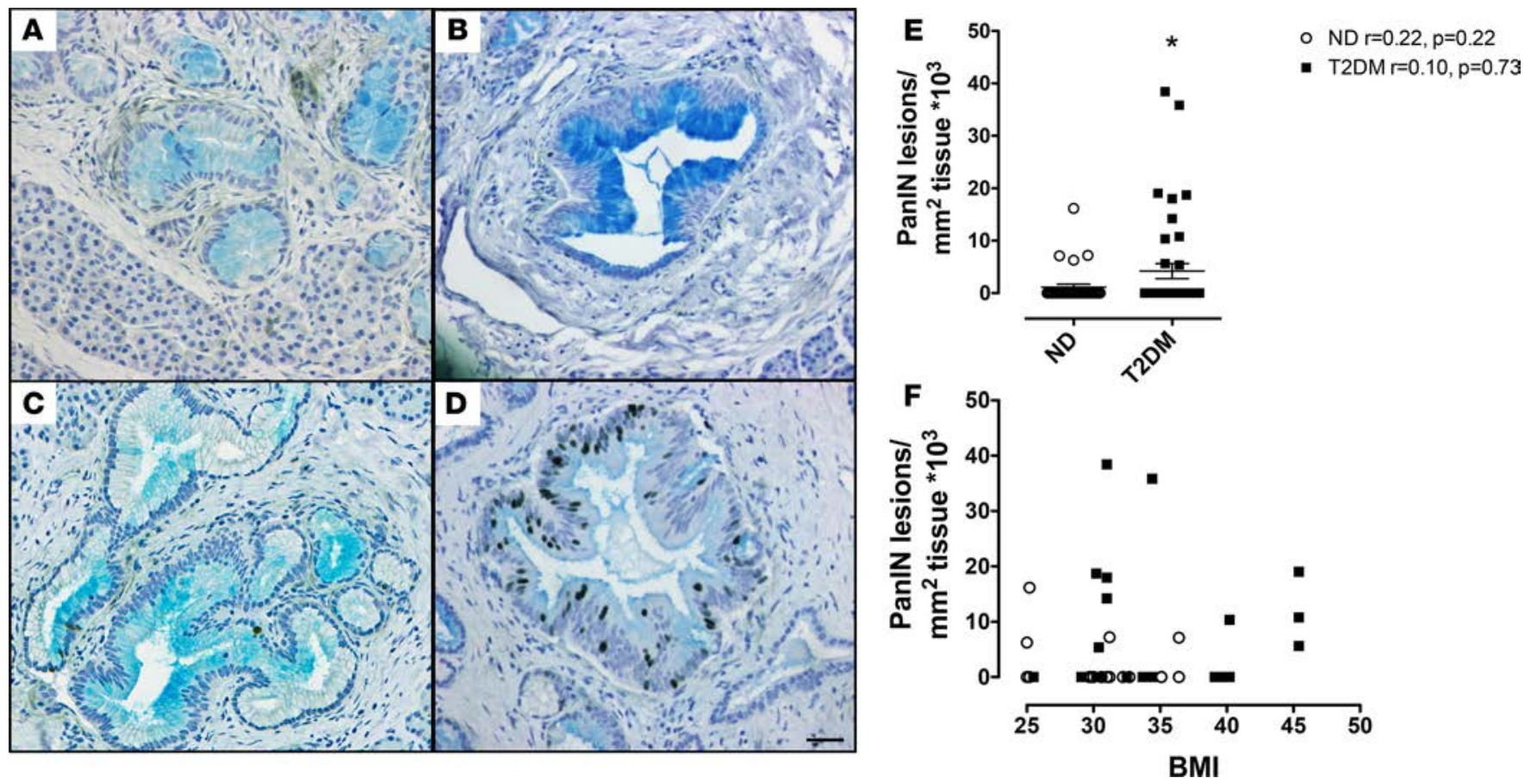

Figure 1. Pancreatic intraepithelial neoplasia (PanIN) lesions are more frequent in type 2 diabetes mellitus (T2DM). (A-D) Examples of PanIN lesions identified in individuals with T2DM (A: donor 6108, low-grade PanIN; B: donor 6114, low-grade PanIN; C: donor 6142, low-grade PanIN, D: donor 6139, lowgrade PanIN; all images acquired with a $\times 20$ lens $[\times 200$ magnification]) stained with Alcian blue to detect mucin deposition, and for insulin (pink) and Ki67 (brown) to mark replicating cells. Scale bars: $50 \mu \mathrm{m}$. (E) Low-grade PanIN lesions were more frequent in T2DM (14 donors; $n=42$ pancreas sections [14 head, 14 body, and 14 tail]) compared with nondiabetic (ND) controls (13 donors, $n=33$ pancreas sections [13 head, 7 body and 13 tail]): $4.2 \pm 1.4$ vs. $1.1 \pm 0.6$ PanIN lesions $/ \mathrm{mm}^{2}$ pancreas $\times 10^{3}, \mathrm{~T} 2 \mathrm{DM}$ vs. ND; ${ }^{*} P<0.05$. Open circles $=\mathrm{ND}$ donors, black squares $=\mathrm{T} 2 \mathrm{DM}$ donors. $(\mathbf{F})$ There was no relationship between PanIN lesions and BMI in either the ND controls (linear regression $r=0.22, P=0.22 ; n=33$ ) or the subjects with T2DM (linear regression $r=0.05, P=0.77 ; n$ $=42)$. Open circles $=$ ND donors, black squares $=$ T2DM donors. Data represent mean \pm SEM; 1 -tailed Student's $t$ test.

(Network for Pancreatic Organ donors with Diabetes [nPOD] pancreas donors are assigned case numbers sequentially), from the donor numbers used in this study (Table 1) it is apparent that ND and T2DM donor pancreata were procured in a random fashion. Hospitalization stay was similar in both groups $(5,879 \pm$ 867 vs. $6,106 \pm 1,003$ minutes, T2DM vs. ND, $P=\mathrm{ns}$ ). Hospitalization time was not known in one T2DM donor (number 6028). The transport time (from cross clamping to processing) was, however, longer in the T2DM donor group $(1,052 \pm 61$ vs. $655 \pm 88$ minutes, T2DM vs. ND, $P<0.001)$ but this, if anything, may have negatively affected Ki67 staining resulting in artificially low numbers (27). Slides were stained in batches of 10 at UCLA, each batch including 5 T2DM and 5 ND pancreas sections. The Ki67 antibody lot used was the same for all sections.

Within the T2DM donor group, with respect to the clinical characteristics, neither age (45.0 \pm 4.5 vs. $44.3 \pm 7.2$ years, high vs. normal PDG replication, $P=\mathrm{ns})$, duration of diabetes $(9.3 \pm 4.4$ vs. $11.8 \pm$ 5.9 years, high vs. normal PDG replication, $P=\mathrm{ns}$ ), gender (high: 2 males, 3 females; normal: 3 males, 6 females), nor BMI (35.9 \pm 3.0 vs. $33.5 \pm 1.7 \mathrm{~kg} / \mathrm{m}^{2}$, high vs. normal PDG replication, $\left.P=\mathrm{ns}\right)$ distinguished the groups. In those 5 T2DM donors that did have increased PDG replication, this was unchanged with age and duration of diabetes. Within the T2DM donor group, hospitalization stay was similar in both high and normal PDG replication groups (5,558 \pm 1,094 vs. 6,079 \pm 1,285 minutes, high vs. normal PDG replication groups, $P=\mathrm{ns})$, as was transport time (1,098 \pm 103 vs. 1,026 \pm 79 minutes, high vs. normal PDG replication, $P=\mathrm{ns}$ ). As noted above, hospitalization time was not known in one T2DM donor (number 6028).

Having excluded technical or case-ascertainment bias to account for large variance in PDG cell replication in T2DM, we then turned to the possibility that pancreatic inflammation in T2DM might account for the difference, since the PDG compartment has been shown to respond with increased proliferation in response to experimentally induced pancreatitis $(9,25)$. Of the 5 T2DM donors with the highest PDG cell replication, 3 (6114, 6133, and 6149) had regions of chronic pancreatitis that were more pronounced than in either the remainder of the T2DM donor sections or in the ND control sections. Notably, none of these 

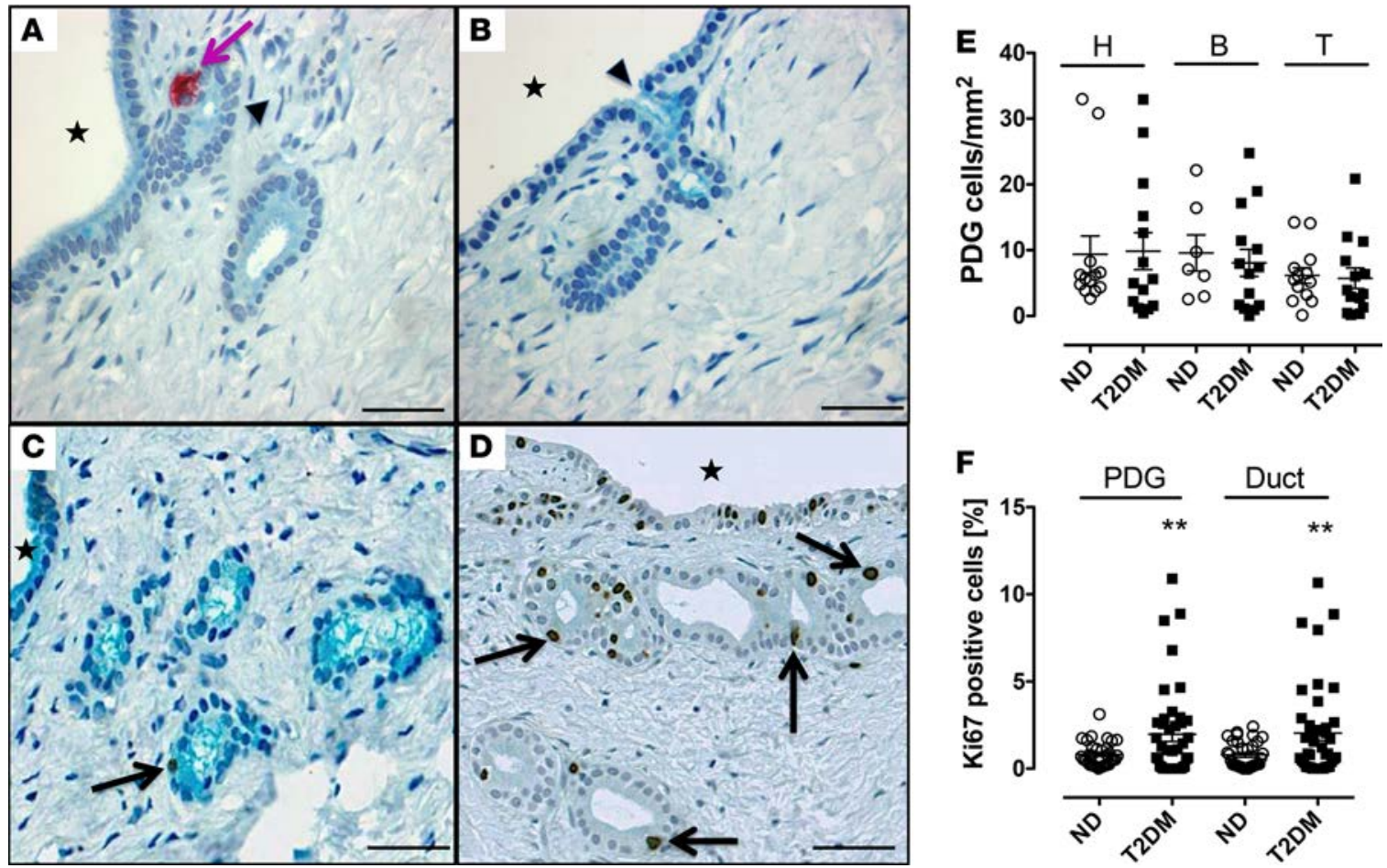

Figure 2. Pancreatic duct glands (PDGs) are present throughout the human pancreas with increased PDG cell replication in type $\mathbf{2}$ diabetes mellitus (T2DM). (A and B) Examples of PDGs (arrows) in cross section in mesenchyme surrounding pancreatic ducts (A and B: donor 6015). PDGs and interlobular duct epithelium (but not intralobular pancreatic ducts) stain positively for mucin (Alcian blue) and are continuous and open into the interlobular duct epithelium (arrowheads); Stars indicate interlobular duct lumen; pink arrow indicates insulin-positive cell in PDG epithelium. Scale bars: $50 \mu \mathrm{m}$. (C and D) Representative examples of the PDC compartment in a nondiabetic (ND) subject (C: donor 6165) and a subject with T2DM (D: donor 6133) stained for Ki67 (brown) and with Alcian blue. Scale bars: $50 \mu \mathrm{m}$. Stars indicate interlobular duct lumen; black arrows indicate Ki67-positive nuclei in the PDG epithelium. Scale bars: $50 \mu \mathrm{m}$. (E) PDGs in human pancreas are present in the head, body, and tail with a comparable abundance in individuals with T2DM and ND controls (head: $9.9 \pm 2.8$ vs. $9.4 \pm 2.8 \mathrm{PDGs} / \mathrm{mm}^{2}$ pancreas, T2DM $[n=14]$ vs. ND $[n=13], P=n s ;$ body: $8.1 \pm 2.1 \mathrm{vs.} 9.6 \pm 2.8 \mathrm{PDCs} / \mathrm{mm}^{2}$ pancreas, T2DM $[n=14]$ vs. ND $[n=7], P=n s ;$ tail: $5.7 \pm 1.6$ vs. $6.1 \pm 1.2 \mathrm{PDCs} / \mathrm{mm}^{2}$ pancreas, T2DM [ $\left.n=14\right]$ vs. ND $\left.[n=13], P=\mathrm{ns}\right)$. Open circles = ND donors, black squares= T2DM donors. (F) The frequency of PDG cell replication and interlobular pancreatic duct replication is increased in T2DM compared with ND controls (PDG: $2.0 \% \pm$ $0.4 \%$ vs. $0.8 \% \pm 0.1 \%$, T2DM $[n=42]$ vs. ND $[n=33]$, ${ }^{*} P<0.01$; interlobular duct: $2.0 \% \pm 0.4 \%$ vs. $0.8 \% \pm 0.1 \%$, T2DM $[n=42]$ vs. ND [ $\left.\left.n=33\right]\right) .{ }^{* *} P<0.01$. Open circles $=$ ND donors, black squares $=$ T2DM donors. Data represent mean \pm SEM; 1-tailed Student's $t$ test.

individuals had known clinical pancreatitis documented in their lifetimes, consistent with accumulating data that subclinical subacute chronic pancreatitis is common in both type I diabetes (T1D) and T2DM, the origin of which remains unknown (28). These findings are therefore consistent with the PDG compartment being activated by pancreatic inflammation, whether originating from the exocrine compartment or with sufficient intensity from the islet compartment and surrounds.

In order to mechanistically substantiate our findings in human pancreas, we turned to the HIP rat model of T2DM.

$P D G$ replication in HIP versus $W T$ rats. HIP rats develop diabetes spontaneously due to high expression of human IAPP and have islet pathology reflective of human disease (17). We fed rats with a high-fat diet that has been shown to accelerate disease development (similar to humans, where obesity is a risk factor) (29) and treated these rats with the diabetes medications exendin- 4 , metformin, or a combination of the two.

Prior to initiation of high-fat diet and treatments, blood glucose levels were comparable in HIP and WT rats. After 12 weeks of high-fat feeding, plasma glucose levels increased to $131 \pm 3 \mathrm{mg} / \mathrm{dl}$ in HIP rats but were unchanged $(102 \pm 4 \mathrm{mg} / \mathrm{dl}$ ) in WT rats (Supplemental Figure 2).

The increased PDG cell replication in T2DM might be induced by inflammatory cytokines and/or as a consequence of metabolic changes that occur in diabetes. To address this, we evaluated the PDG compartment in the prediabetic HIP rat model of T2DM (17). As in human pancreas, the PDGs in rats were identified as crypt-like invaginations embedded in mesenchyme surrounding interlobular ducts and composed of columnar epithelium (Figure 3A). We quantified PDG cell replication in this model at 22 
Table 1. Characteristics of human subjects with and without type 2 diabetes

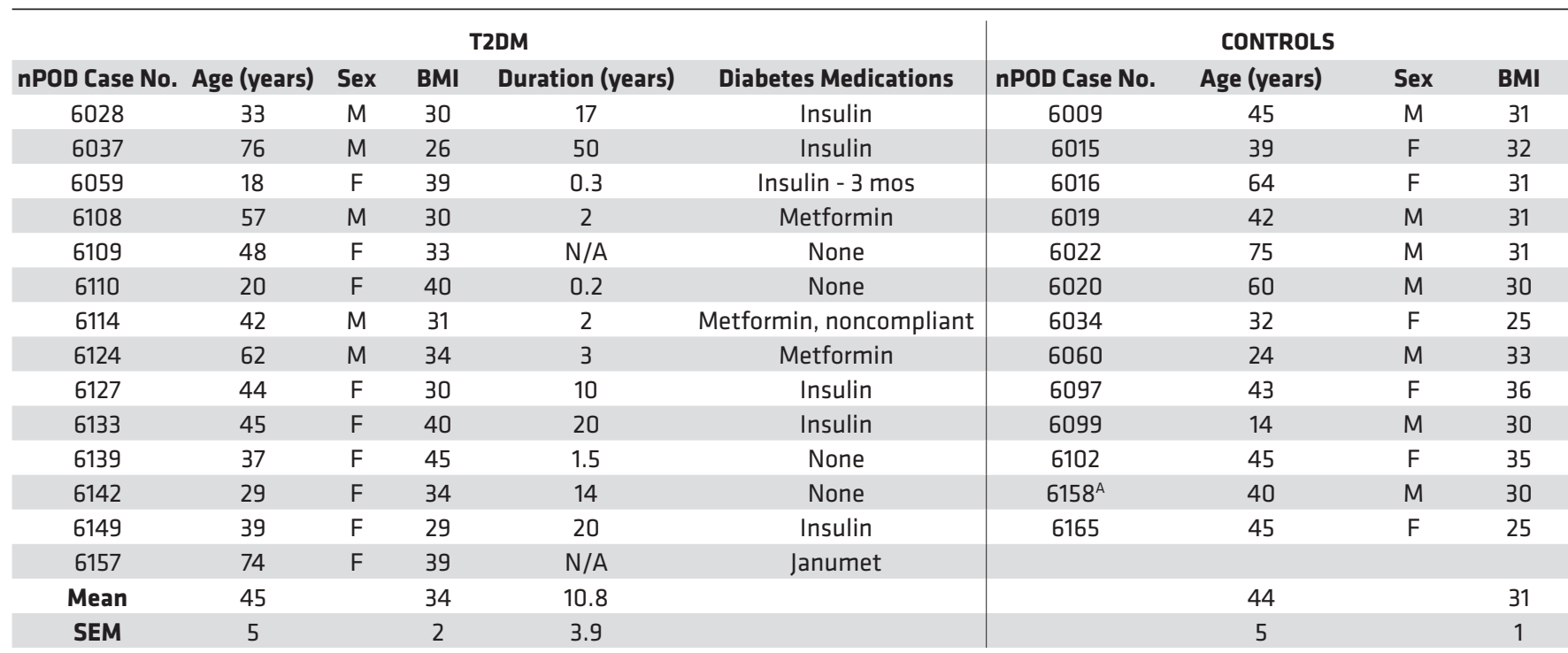

A6158 was negative for autoantibodies by RIA but positive by ELISA. PDG, pancreatic duct gland; T2DM, type 2 diabetes mellitus; nPOD, Network for Pancreatic Organ donors with Diabetes; HIP, human IAPP transgenic; PanIn, pancreatic intraepithelial neoplasia; IPMN, intraductal papillary mucinous neoplasia; $\mathrm{CXCL}$, chemokine (C-X-C motif) ligand; PF4, platelet factor 4.

weeks of age, coinciding with either prediabetes or early onset of diabetes but when $\beta$ cell apoptosis has increased for 10 weeks (17). Under these conditions PDG cell replication was 2-fold increased in HIP compared with WT rats $(7.9 \% \pm 0.6 \%$ vs. $4.3 \% \pm 0.5 \%$, HIP vs. WT, $P<0.05)$ (Figure $3 \mathrm{~B})$. Also in common with humans with T2DM, replication of interlobular pancreatic duct cells was increased in the HIP rats $(4.6 \% \pm 0.5 \%$ vs. $2.1 \% \pm 0.1 \%$, HIP vs. WT, $P<0.01)$ (Figure $3 \mathrm{C}$ ). Consistent with selection of HIP rats in the prediabetes age range but when $\beta$ cell apoptosis is already increased, the increased PDG and interlobular duct cell replication in HIP rats was independent of blood glucose concentration $(r=0.08$, $P=0.88$, data not shown).

Since glucose levels were relatively elevated in the HIP rats, we set out to determine whether hyperglycemia could be the major trigger of proliferation in the PDGs. We infused WT rats via indwelling catheter to achieve a plasma glucose concentration of $\sim 250 \mathrm{mg} / \mathrm{dl}$ and plasma insulin concentrations ranging from 2 to $4 \mathrm{nmol} / 1$ over 72 hours (Supplemental Figure 3). There was no increase in $\beta$ cell apoptosis (data not shown). The combined hyperglycemia and hyperinsulinemia had no effect on PDG cell replication $(1.4 \% \pm 0.6 \%$ vs. $2.8 \% \pm 1.3 \%$, glucose vs. saline) or interlobular pancreatic duct cell replication $(0.7 \% \pm 0.2 \%$ vs. $0.8 \% \pm 0.1 \%$, glucose vs. saline) (Figure $4, \mathrm{~A}, \mathrm{~B}, \mathrm{D}$, and $\mathrm{E})$. As a positive control, consistent with prior reports in rodents $(30,31)$, the same duration of hyperglycemia induced a 7 -fold increase in $\beta$ cell replication $(0.7 \% \pm 0.1 \%$ vs. $0.1 \% \pm 0.1 \%$, glucose vs. saline, $P<0.01)$ (Figure $4 \mathrm{C}$ ). Collectively, these studies imply that the signals might arise as a result of increased $\beta$ cell stress (ER stress, oxidative stress, etc.) inducing increased PDG cell replication.

To address what these stimulatory factors might be, we performed microarray analysis of islet lysates collected from 4.5- to 5-month-old prediabetic HIP rats $(n=2)$ and age-matched WT controls $(n=2)$.

Proliferative actions of chemokines on human pancreatic ductal epithelium. The results of the microarray analysis revealed several chemokines as candidates, including CXCL1 and CXCL10 that have been reported to be increased in the circulation of patients with T2DM (11-13). RNA microarray profiles from islets isolated from prediabetic HIP rats and ND WT rats were found to be consistent with the human data, with CXCL1 (108-fold) and CXCL10 (4-fold) overexpressed in HIP rat islets (Supplemental Figure 4A). All original microarray data were deposited in the NCBI's Gene Expression Omnibus (GEO GSE90779). This analysis also revealed platelet factor 4 (PF4, also known as CXCL4) as an additional candidate molecule being 7-fold overexpressed in islets of HIP rats.

We confirmed this finding by RT-PCR. mRNAs for CXCL1, -4 , and -10 were found in both rat and 

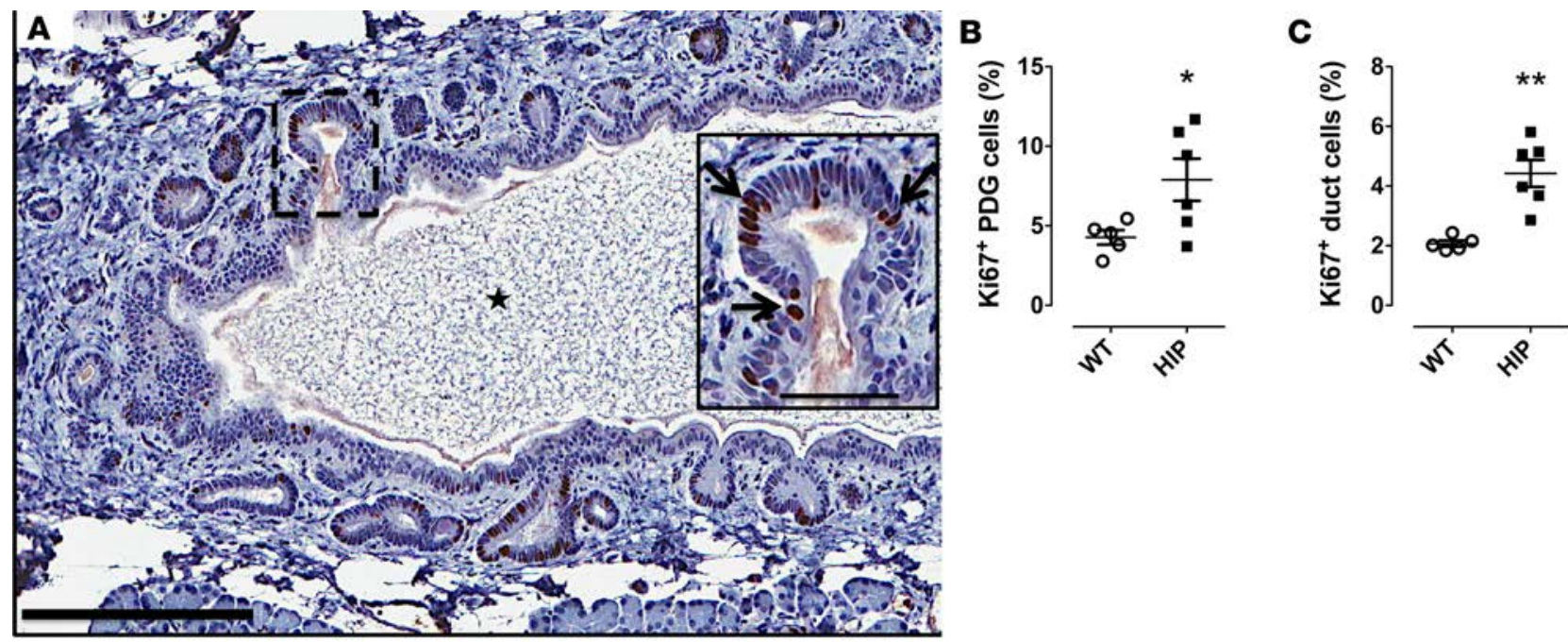

Figure 3. Pancreatic duct gland (PDC) cell replication is increased in the human-IAPP-transgenic (HIP) rat model of type 2 diabetes mellitus (T2DM). (A) Sections of pancreas from a HIP rat showing PDGs in the mesenchyme surrounding the pancreatic duct into which they open. Section is stained for Ki67 with a hematoxylin counterstain. Inset shows a higher-power view of a PDG with frequent Ki67-positive nuclei (black arrows). The star indicates the interlobular duct lumen. Scale bars: $200 \mu \mathrm{m}$ and $50 \mu \mathrm{m}$ (inset). (B and C) Consistent with T2DM, cell replication evaluated by Ki67 is increased in both the PDG and interlobular duct cell epithelium in the HIP rat $(n=6)$ compared with WT $(n=5)$ controls, coincident with increased $\beta$ cell apoptosis but before onset of diabetes in many animals. Data represent mean $\pm \mathrm{SEM}$. ${ }^{*} P<0.05$, ${ }^{* *} P<0.01$ by 2 -tailed Student's $t$ test.

human isolated islets (Supplemental Figure 4B and Supplemental Figure 5). There was a 4.5-fold increase of Cxcl1 and a 36-fold increase of Pf4 in HIP rat islets compared with WT. These chemokines were also expressed in isolated human islets; the mRNA levels were quite variable in both ND and T2DM islets (Supplemental Figure 5).

On the other hand, we confirmed the presence of chemokine receptors in PDG. We detected CXCR2 in HIP rat pancreas by IHC (Figure 5C). In human T2DM pancreas CXCR2 (receptor for CXCL1) and CXCR3 (receptor for CXCL4 and -10) were found by immunostaining (Figure 5, A and B). Moreover, we confirmed the presence of both CXCR2 and CXCR3 receptors in HPDE cells (32) by Western blotting (Figure 5, D and E, respectively). Of note, the protein levels of these receptors were not changed by the treatment with chemokines for up to 96 hours.

To investigate whether chemokines can induce proliferation of ductal replication, we treated HPDE cells for 96 hours with CXCL1 or epidermal growth factor (EGF) as a positive control. Treatment with EGF increased cell density $2.0 \pm 0.1$-fold $(P<0.001)$. Treatment with CXCL1 increased cell density 1.6 \pm 0.1 -fold compared with vehicle alone $(P<0.001)$ (Figure 6A). Similarly, CXCL4 and CXCL10 incuba-
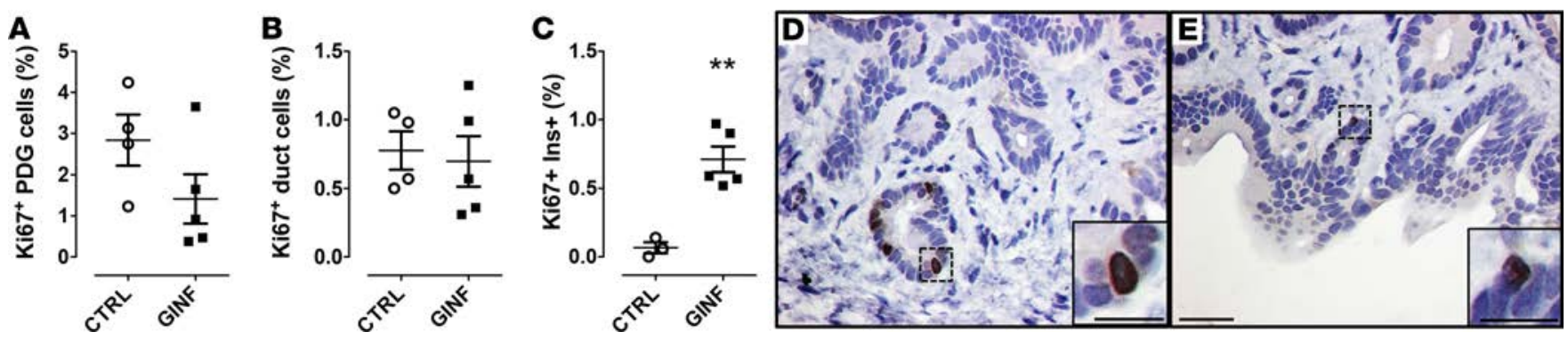

Figure 4. Pancreatic duct gland (PDG) cell replication is not increased following chronic glucose infusion in WT rats. Following 72-hour chronic glucose infusion (GINF), neither PDG (A) nor interlobular duct cell replication (B) was increased, further excluding hyperglycemia/hyperinsulinemia as the driving signals. However, $\beta$ cell replication was increased 7-fold (C) during the GINF serving as a positive control for the proproliferative actions of hyperglycemia. Representative examples of replication in the PDG compartment in control (D) and GINF-treated (E) rats. Sections are stained for Ki67 with a hematoxylin counterstain. Insets show higher-power views of PDGs, each with a Ki67-positive nucleus. Scale bars: $50 \mu \mathrm{m}, 25 \mu \mathrm{m}$ (inset in D), and $20 \mu \mathrm{m}$ (inset in E). Control (CTRL) rats $n=4$, GINF-treated rats $n=5$. Data represent mean \pm SEM. ${ }^{* *} P<0.01$ by 2 -tailed Student's $t$ test. 
T2D, 6133

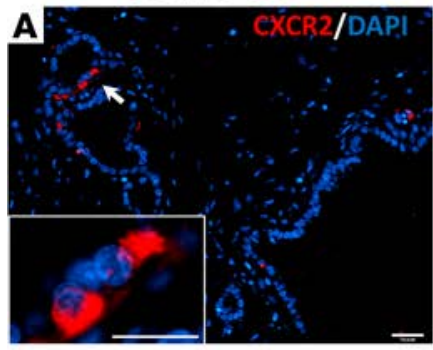

T2D, 6114

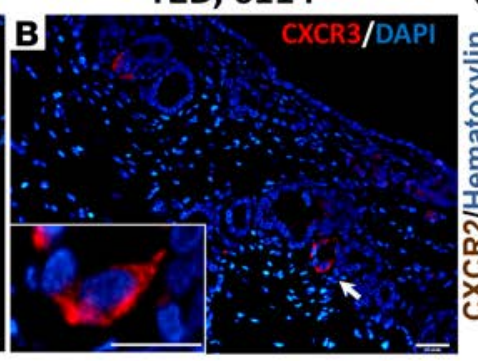

C

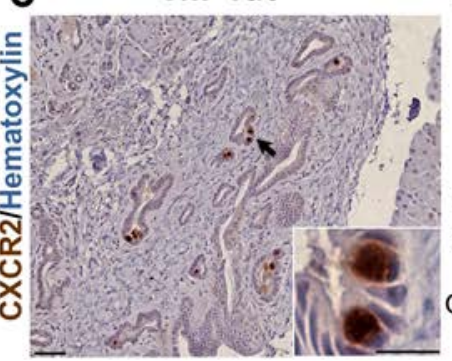

D

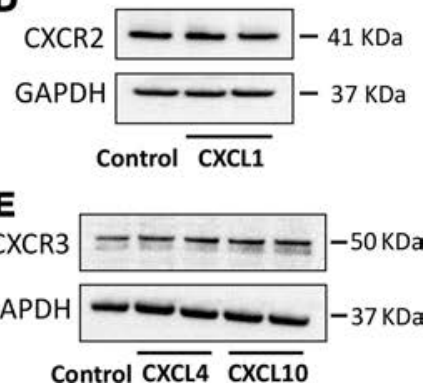

Figure 5. The chemokine receptors are expressed in pancreatic duct glands (PDGs) and pancreatic ductal cells. (A and B) are representative images of immunofluorescent staining for CXCR2 and CXCR3 in PDG compartment of pancreas from 2 subjects with type 2 diabetes mellitus (T2DM), nPOD donor 6133 and donor 6114, respectively. (C) A representative image of immunohistochemical staining for CXCR2 in PDGs in diabetic human-IAPP-transgenic (HIP) rat pancreas ( 3 independent staining experiments were performed, total $n=7$ rats). Western blots confirming the presence of both CXCR2 (D) and CXCR3 (E) receptors in human pancreatic ductal epithelial (HPDE) cells ( 2 independent experiments were performed). Insets in A-C indicate the high-power images of the areas indicated by white arrows (A and $\mathbf{B}$ ) and black arrow (C) in the low-power images. Scale bars: $100 \mu \mathrm{m}, 50 \mu \mathrm{m}$ (insets in $\mathbf{A}$ and $\mathbf{B}$ ), and $25 \mu \mathrm{m}$ (inset in $\mathbf{C}$ ).

tion resulted in a $1.2 \pm 0.1$-fold and $1.3 \pm 0.1$-fold increase in proliferation of HPDE cells versus control $(P<0.01$ and $P<0.05$, respectively). Of note, we identified in HIP rats islets in close proximity to PDGs that had a high frequency of replication (Supplemental Figure 6), supporting the postulate that chemokine release from islets has a stimulatory effect on PDG replication.

The proproliferative effect is specific to chemokines since, by contrast, proinflammatory cytokines (IL-1 $\beta$, TNF- $\alpha$, and INF- $\gamma$ ) alone or in combination did not alter growth rates of HPDE cells over 96 hours at low concentrations, and at high concentration have the tendency to decrease the number of HPDE cells, most likely due to cytotoxic effects (data not shown). Furthermore, Western blot analysis revealed a time-dependent phosphorylation of the proproliferative MAP kinases ERK1/2 in HPDE cells incubated with CXCL1 (Figure 6B and Supplemental Figure 7A), which was blocked by anti-CXCL1 antibody (33) (Supplemental Figure 7B).

As previously published, a similar mechanism underlies the proproliferative effect of exendin- 4 on HPDE cells (25).

Effects of GLP-1 and metformin treatment on PDG proliferation. As previously stated, pancreatitis is more common in patients with T2DM (1-4). Pancreatitis has been reported in some clinical studies to increase further upon treatment with GLP-1-based therapy for diabetes, while others imply a decreased risk of pancreatitis with metformin (19-21).

Treatment of HIP and WT rats with metformin alone had no effect on glucose concentrations when compared with the control groups (140 \pm 2 and $107 \pm 4 \mathrm{mg} / \mathrm{dl}$, respectively). Exendin- 4 treatment as well as the combined administration of exendin- 4 and metformin lowered plasma glucose levels in WT rats (94 \pm 2 and $87 \pm 3 \mathrm{mg} / \mathrm{dl}$, respectively, $P<0.05$ vs. control) and were able to restrain the increase in HIP rats (113 \pm 1 and $112 \pm 2 \mathrm{mg} / \mathrm{dl}$, respectively, both $P<0.05$ vs. control).

Exendin-4, a GLP-1 receptor agonist, increased PDG cell replication $(17.4 \% \pm 0.6 \%$ vs. $7.9 \% \pm$ $0.6 \%$, exendin- 4 vs. saline, $P<0.001)$ and interlobular duct replication $(6.2 \% \pm 0.7 \%$ vs. $4.6 \% \pm 0.5 \%$, exendin- 4 vs. saline, $P<0.05$ ) in HIP rats (Figure 7A). Exendin-4 also increased PDG cell replication $(10.9 \% \pm 1.9 \%$ vs. $4.3 \% \pm 0.5 \%$, exendin- 4 vs. saline, $P<0.01)$ and interlobular duct epithelium replication $(5.9 \% \pm 1.3 \%$ vs. $2.1 \% \pm 0.1 \%$, exendin- 4 vs. saline, $P<0.05)$ in WT rats (Figure $7 \mathrm{~B})$. The increase in PDG and interlobular duct cell replication by exendin-4 treatment was fully suppressed by addition of metformin to the treatment in both WT and HIP rats. Representative examples of PDG replication in treated and nontreated rats are shown for WT (Supplemental Figure 8) and HIP (Supplemental Figure 9). It is worth mentioning that although the mRNA levels of CXCL1 and -4 were higher in isolated HIP islets, in vitro treatment of isolated HIP islets with exendin-4, metformin, and combination of the two, did not appear to have an effect on the mRNA levels of these chemokines (data not shown).

So, despite the fact that exendin-4 lowered blood glucose levels in HIP rats on a high-fat diet, PDG cell replication was still markedly increased, confirming that hyperglycemia is not a major trigger for PDG cell replication. 
A

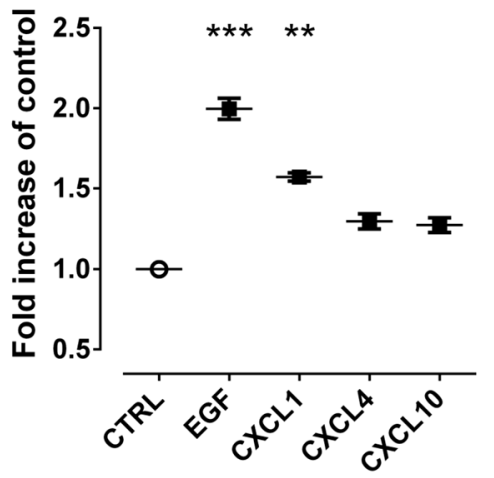

B

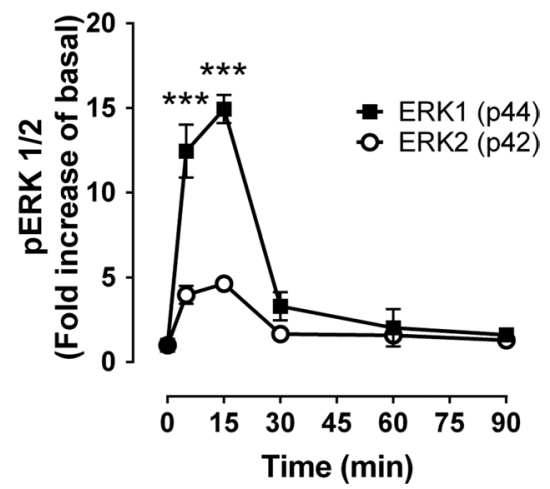

Figure 6. Chemokines increase human pancreatic duct cell replication. (A) To evaluate the potential link between $\beta$ cell apoptosis and increased duct cell replication in type 2 diabetes mellitus, human pancreatic duct cell epithelia (HPDE) cells were exposed to the 3 primary chemokines, CXCL1, -4 , and -10 (found to be overexpressed in excess in the islet of the human-IAPP-transgenic (HIP) rat, Supplemental Figure 4) for 96 hours, and cell growth was measured using a cell viability assay (MTT, see Methods). Epidermal growth factor (EGF) was used as a positive control. Data represent mean \pm SEM from 3 independent experiments. ${ }^{* *} P<0.01,{ }^{* *} P<0.001$ versus control (CTRL) by 1-way ANOVA with Dunnett's post-hoc test. (B) CXCL1 increased phosphorylation of ERK1/2 in a time-dependent manner; 0 time point is a baseline (cells were not treated with chemokine). Data represent mean \pm SEM from 3 independent experiments. ${ }^{* *} P<0.001$ versus 0 time point for both ERK1 and ERK2 by 1-way ANOVA with Dunnett's post-hoc test.

\section{Discussion}

In the present study, we sought to investigate the potential link between islet inflammation characteristic of T2DM and proliferative changes in the exocrine ductal tree as a potential mechanism for the increased risk of pancreatitis in T2DM.

First, we examined the frequency of PanIN lesions in pancreas from humans with and without T2DM since these common intraductal lesions are a recognized consequence of abnormal increased proliferation and, when of sufficient size in smaller caliber ducts, may impair ductal enzyme outflow with increased risk for pancreatitis. Having established that PanINs were more frequent in T2DM, we then evaluated proliferation in the ductal tree, and in particular the PDG compartment since this has been proposed as a stem cell niche that, when chronically stimulated, may give rise to PanIN-like lesions $(8,25)$. The PDG compartment was readily detectable throughout the human pancreas, with a 2-fold increase in PDG cell replication in individuals with T2DM compared with ND controls. There was also increased replication of epithelia lining ducts adjacent to PDGs in T2DM, consistent with a prior study that revealed increased duct cell replication in T2DM and in obesity (7). Collectively, these findings are consistent with the concept that PDGs deliver cells to adjacent
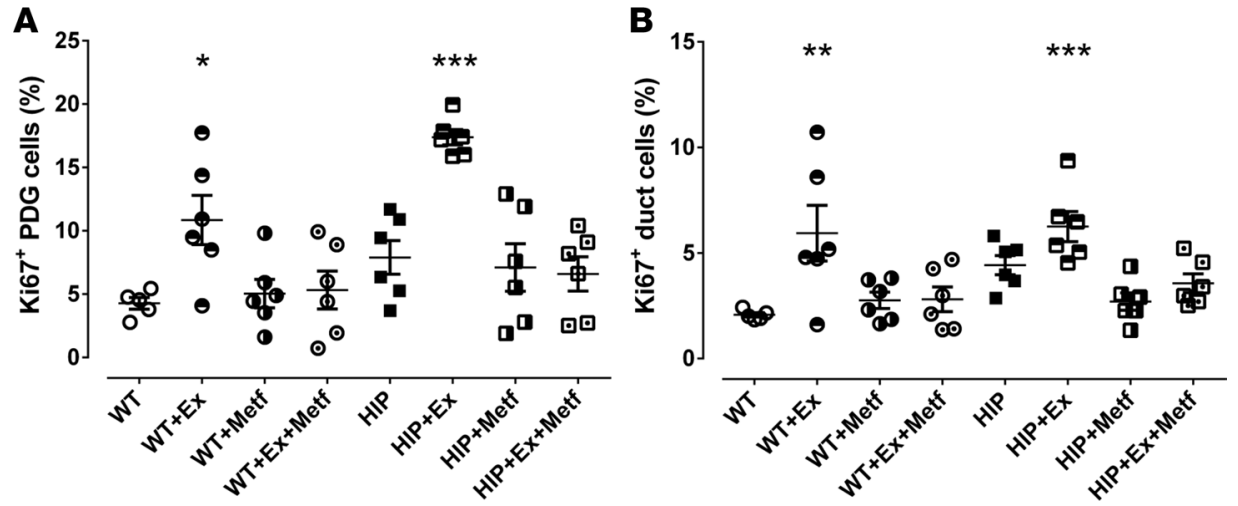

Figure 7. The actions of exendin-4 and metformin on pancreatic duct glands (PDGs) and interlobular duct replication in human-IAPP-transgenic (HIP) rats and WT controls. (A and B) Twelve weeks of treatment with the glucagon-like peptide- 1 mimetic exendin-4 (Ex) induced an increase in PDC (A) and interlobular duct (B) cell replication in control WT rats and caused a further increase in replication in HIP rats. Metformin (Metf) treatment over the same 12 weeks suppressed the Ex-induced proliferation in WT and HIP rats in both PDGs and interlobular ducts. WT $n=5$, WT+Ex $n=6$, WT + Metf $n=6$, WT+Ex+Metf $n=6, \mathrm{HIP} n=6$, HIP+Ex $n=6$, HIP+Metf $n=6$, HIP+Ex+Metf $n=6$. Data represent mean $\pm \mathrm{SEM} .{ }^{*} P<0.05,{ }^{* *} P<0.01$, ${ }^{* * *} P<0.001$ versus WT saline control by 1-way ANOVA with Dunnett's post-hoc test. 
duct epithelium and that PanIN-like lesions might develop as a consequence of sustained increased PDG replication. Consistent with this, in both the current study and that in individuals with T1D (34), we did not see any increase in cell death in the PDG compartment despite increased cell replication (data not shown). The increased PDG cells produced therefore initially palisade and develop PanIN-like lesions in the ductal tree and then apparently slough off into the duct. The latter has been investigated as a means to detect the genetic progression of PanIN cells towards pancreatic cancer (35).

It is equally likely that sustained PDG replication could give rise to interlobular duct dysplasia, a precursor lesion of IPMN. While IPMN and PanIN lesions have distinct morphological and gene expression profiles, the question has been raised as to whether the early steps of IPMN and PanIN initiation may be shared, with the loss of cellular identity possibly providing the common link (36). In keeping with this concept, when compared with the ND group presented here, more of the T2DM cases showed evidence of reactive ductal changes and IPMN, and the ductal tree was more extensively affected.

We next turned to the hypothesis that chemokines released by $\beta$ cell stress and apoptosis characteristic of T2DM might serve as the driver for PDG and ductal replication by activating regenerative programs. In a classical model of regeneration, the bisected planaria requires apoptosis to induce proliferation and regeneration (37). Local inflammation is associated with increased proliferation in the well-characterized stem cell compartments of the ileum and colon (38). To investigate this, we turned to the HIP rat model of T2DM. In the HIP rat model of T2DM, pancreatic $\beta$ cells are transgenic for human IAPP, a protein that is coexpressed and secreted with insulin (39). Human, but not rodent, IAPP is amyloidogenic and in individuals that develop T2DM IAPP forms intracellular toxic membrane-permeant oligomers that induce $\beta$ cell stress and apoptosis that contribute to the $\beta$ cell deficit and impaired insulin secretion in T2DM. The islet pathology and metabolic progression from ND to impaired fasting glucose and then diabetes characteristic of T2DM is reproduced in the HIP rat (17).

PDG replication was increased 2-fold in the HIP rat in the prediabetic state, when $\beta$ cell stress and increased apoptosis are already established, implying islet inflammation rather than deranged metabolism as the stimulus for PDG replication. This was further reinforced by the absence of an increase in PDG replication during sustained hyperglycemia and hyperinsulinemia in the absence of islet inflammation or increased $\beta$ cell apoptosis in WT rats. Finally, chemokines released in excess by islets in T2DM were proproliferative in human pancreatic duct cells, through the MAP kinase pathway. Taken together, these findings support the postulate that cytokines released as a consequence of longstanding $\beta$ cell stress and apoptosis in T2DM might sustain increased proliferation in the pancreatic duct tree, in particular the PDG compartment.

Recently, epidemiological studies and clinical trials have suggested that metformin therapy may decrease and GLP-1-based therapy may increase the frequency of pancreatitis in T2DM $(19,20)$. Metformin inhibits $\beta$ cell apoptosis in isolated islets from individuals with T2DM and in vivo in the HIP rat (40). While GLP-1 inhibits $\beta$ cell apoptosis, it has been reported to increase proliferation of PDGs and human pancreatic duct epithelium (25). As previously reported, the GLP-1 mimetic exendin-4 increased PDG replication in ND rats (25), but now reported here also in HIP rats despite being effective in treating hyperglycemia. By use of an HPDE cell line, the mechanism of GLP-1-induced replication was previously established to be through the same proproliferative signaling pathway now shown here to be activated by chemokines, and that metformin constrained the effect of GLP-1 on this proproliferative pathway (25). Consistent with those prior findings, here we report that metformin attenuated the GLP-1induced increase in PDG cell replication when given concurrently with exendin-4. Also consistent with these findings, sitagliptin has been shown to increase duct cell replication, an action that was opposed by concurrent use of metformin (22).

In summary, PanIN lesions were more commonly seen in T2DM donors in our study. T2DM is also characterized by increased PDG replication. While increased PDG cell replication is a proposed source of PanIN-like lesions, this association is yet to be fully established. Chemokines released by the islet in T2DM are shown to induce proliferation in human pancreatic ductal epithelium. We propose that the ongoing $\beta$ cell stress and apoptosis in T2DM may induce an ongoing repair program by PDGs, and likely other cell types, that serve as a link to increased risk of PanIN development with potentially delayed exocrine outflow, serving to increase the risk of pancreatitis in T2DM. In conclusion, we have uncovered a potential explanation for the increased frequency of PanINs and increased frequency of pancreatitis in patients with T2DM, specifically proliferative actions of chemokines released by stressed $\beta$ cells acting in a paracrine manner on local replication-competent compartments, most notably the PDGs. 
Table 2. The numbers of cells counted in the PDGs, interlobular, and intralobular ducts in the donors with T2DM and nondiabetic controls

\begin{tabular}{|c|c|c|c|c|}
\hline T2DM & Head & Body & Tail & Total \\
\hline PDG cells, total & 15,522 & 12,464 & 8,634 & 36,620 \\
\hline PDG cells, mean (range) & $1,109(69-3,242)$ & $890(0-1,887)$ & $617(15-2,320)$ & \\
\hline Interlobular duct cells, mean (range) & $1,510(214-4,449)$ & $1,367(0-2,545)$ & $1,070(59-1,721)$ & \\
\hline Intralobular duct cells, total & 40,082 & 36,095 & 32,624 & 108,801 \\
\hline Intralobular duct cells, mean (range) & $2,863(1,651-5,234)$ & $2,578(864-5,185)$ & $2,330(1,245-3,764)$ & \\
\hline PDG cells, mean (range) & $1,256(634-4,085)$ & $1,472(848-2,534)$ & $886(246-1,621)$ & \\
\hline Interlobular duct cells, total & 26,535 & 14,133 & 24,990 & 65,658 \\
\hline Interlobular duct cells, mean (range) & $2,041(705-2,954)$ & $2,019(882-4,031)$ & $1,922(497-4,452)$ & \\
\hline Intralobular duct cells, total & 38,148 & 23,035 & 38,441 & 99,624 \\
\hline Intralobular duct cells, mean (range) & $2,934(1,526-4,930)$ & $3,291(2,570-4,390)$ & $2,957(1,858-4,873)$ & \\
\hline
\end{tabular}

PDG, pancreatic duct gland; T2DM, type 2 diabetes mellitus; ND, nondiabetic.

\section{Methods}

\section{Studies}

Humans. Fourteen pancreata from individuals with T2DM and 13 pancreata from ND controls matched by age, sex, and BMI were procured from brain-dead organ donors by the Juvenile Diabetes Research Association nPOD coordinated through the University of Florida in Gainesville, Florida, USA (Table 1). All procedures were in accordance with federal guidelines for organ donation and the University of Florida IRB. To identify and score the PanIN lesion density, 6 pancreatic sections were evaluated per case by an experienced pancreatic pathologist (DD) blinded as to the group. Two sections were evaluated from the head, body, and tail of the pancreas from each case, one of which was stained with Alcian blue and for insulin and Ki67, and the other by H\&E.

Rats. Studies were approved by the UCLA IACUC. The generation of HIP rats was described in Butler et al. (41). Rats were bred at UCLA and were housed individually with a 12-hour light/dark cycle. Twentyfour male HIP rats (17) and 23 WT control male Sprague Dawley rats (WT rats) were studied. At 10 weeks of age, rats started a high-fat diet ad libitum (60\% fat, $20 \%$ protein, and $20 \%$ carbohydrates; Research Diets, D12492) and were randomly assigned to 1 of 4 treatments administered for 12 weeks. Treatments were either daily injections of $10 \mu \mathrm{g} / \mathrm{kg}$ body weight exendin-4 (ChemPep) ( $n=6$ for WT, $n=6$ for HIP), oral administration of $150 \mathrm{mg} / \mathrm{kg}$ body weight metformin mixed with the food (Toronto Research Chemicals) ( $n=6$ for WT, $n=6$ for HIP), exendin- 4 and metformin as above ( $n=6$ for WT, $n=6$ for HIP), or saline injections ( $n=5$ for WT and $n=6$ for HIP).

\section{Chronic glucose-infusion experiments in WT rats}

In 16-week-old WT rats $(n=9)$ chronic indwelling right internal jugular vein and left carotid artery catheters were implanted as previously described (42). Glucose was infused $(n=5)$ to maintain arterial glucose at $\sim 250 \mathrm{mg} / \mathrm{dl}$ for 72 hours versus saline infused in controls $(n=4)$ (Supplemental Figure 3A). Plasma insulin levels increased markedly in the glucose-infused group and remained unchanged in the controls (Supplemental Figure 3B). After 72 hours, the animals were euthanized with an overdose of pentobarbital sodium (Nembutal, Abbot Laboratories) and pancreata were rapidly removed and processed as described below. Plasma glucose concentrations were measured by the glucose oxidase method (YSI Glucose Analyzer).

\section{Immunostaining}

Human pancreas. The nPOD standardized preparation procedure for pancreata recovered from cadaveric organ donors has been reported (43). Rat pancreas was procured as previously described (25). Human pancreatic sections $(4 \mu \mathrm{m})$ were treated with mouse anti-Ki67 $\left(1: 25,4^{\circ} \mathrm{C}\right.$ overnight, Dako, catalog M7240, clone MIB-1, lot number 00070375) and then biotin donkey anti-mouse (1:100, room temperature for 1 hour, The 
Jackson Laboratory) followed by peroxidase staining (Vector Peroxidase Standard PK-4000, Vector Laboratories Inc.). Slides were treated with rabbit anti-insulin $\left(1: 200,4^{\circ} \mathrm{C}\right.$ overnight, Cell Signaling, catalog $\left.3014 \mathrm{~S}\right)$ followed by biotin donkey anti-rabbit (1:100, The Jackson Laboratory) using alkaline phosphatase for color development (Vector Laboratories Inc.), and then incubated with Alcian blue solution $\left(4^{\circ} \mathrm{C}\right.$ overnight, Electron Microscope Sciences) and counterstained with hematoxylin.

To detect CXCR2 and CXCR3 we treated pancreatic sections with either rabbit anti-CXCR2 (1:100, Abcam, ab65968) or mouse anti-CXCR3 (1:500, Abcam, ab64714, clone 2Ar1), followed by the appropriate secondary antibodies (Jackson ImmunoResearch) conjugated to Cy3 (1:200). Slides were mounted using Vectashield with DAPI (H-1200, Vector Labs), viewed using a Leica DM6000 microscope (Leica Microsystems), and images were acquired at $\times 200$ magnification $(\times 20$ objective $)$ using a Hamamatsu OrcaER camera (C4742-80-12AG, Indigo Scientific) and Openlab software (Improvision).

Rat pancreas. Ki67 was detected in rat tissue by IHC using mouse anti-Ki67 (1:25, $4^{\circ} \mathrm{C}$ overnight, Dako, catalog M7248, clone MIB-5), biotin donkey anti-mouse (1:100, room temperature for 1 hour, The Jackson Laboratory) followed by peroxidase staining (Vector Peroxidase Standard PK-4000, Vector Laboratories Inc.). Slides were analyzed using the Ariol SL-50 automated slide scanner (Leica Microsystems) to quantify the amount of positive staining for each area of interest. Total cell counts were divided by the total tissue area analyzed $\left(\mu \mathrm{m}^{2}\right)$. Manual counting was carried out for $n=20$ slides to ensure accuracy of the system. In total, 7,028 PDG cells and 250,847 main duct cells were counted.

Chemokine receptor expression in diabetic HIP rat pancreas was detected by IHC. Sections were incubated overnight at $+4^{\circ} \mathrm{C}$ with rabbit anti-CXCR2 (1:100, Abcam, ab65968), followed by biotin-conjugated donkey anti-rabbit (1:100, 1 hour at room temperature, The Jackson Laboratory), and then by peroxidase staining (Vector Peroxidase Standard PK-4000) using DAB substrate. Slides were coverslipped using Permount and analyzed using a Zeiss Axio microscope.

\section{Pancreas morphology and PDG replication}

The slides stained for Ki67 and insulin were digitally scanned using Aperio ScanScope (Aperio Technologies Inc.). Analysis was performed using Aperio ImageScope version 11.0.2.725, 3 sections per case, 1 each from the head, body, and tail. All ducts with an associated PDG compartment were identified on each section. The number of PDG, interlobular, and intralobular duct cells was manually counted, as was the number of those cells staining for Ki67. The number of PDG, interlobular, and intralobular duct cells counted in the T2DM and ND donor pancreas sections is outlined in Table 2.

\section{PCR}

Pancreatic islets from WT and HIP rats were isolated according to the protocol described previously (44). Two hundred islets were manually picked and lysed in $350 \mathrm{ml}$ of RLT buffer (Qiagen RNeasy MiniKit) supplemented with $1 \% \beta$-mercaptoethanol, and mRNA was isolated according to the manufacturer's instructions. cDNA was prepared using Superscript III (Invitrogen). Real-time quantitative PCR was performed using FAST SYBRGreen master mix and ABI7900HT or QuantStudio 6 Flex equipment from Applied Biosystems. The primers used are listed in Supplemental Table 1.

\section{HPDE cells}

HPDE cells were a gift made available by Ming-Sound Tsao, University of Toronto, Toronto, Canada, and were maintained in keratinocyte serum-free media supplemented with bovine pituitary extract and human EGF (17005-042, Invitrogen) at $37^{\circ} \mathrm{C}$ with $5 \% \mathrm{CO}_{2}$. Cell proliferation was determined by measuring cell viability with 3-(4,5-dimethylthiazol-2-yl)-2,5-diphenyltetrazolium bromide (MTT; Sigma-Aldrich, M5655). Recombinant human CXCL1, -4 and -10 (catalog 275-GR-10, 795-P4-025, and 266-IP-010, respectively, R\&D Systems) were used at $100 \mathrm{ng} / \mathrm{ml}$, exendin-4 at 5, 10, 50, and $100 \mathrm{nM}$ (E7144, Sigma-Aldrich), and metformin at 5, 10, 50, and $100 \mu \mathrm{M}$ (M258815, Toronto Research Chemicals). Cytokines were used at 0.02 and $2 \mathrm{ng} / \mathrm{ml}$ (IL-1 $\beta$ ) and 0.08 and $8 \mathrm{ng} / \mathrm{ml}$ (TNF- $\alpha$ and INF- $\gamma$ ) (I2393, T5944, and I2375, Sigma-Aldrich). For combined treatment with cytokines, low and high concentrations were used. Concentrations for the chemokines CXCL1, -4 , and -10 were based on previously published data related to diabetes. The concentrations described range from $1 \mathrm{ng} / \mathrm{ml}$ (CXCL1) (45) to $100 \mathrm{ng} / \mathrm{ml}$ (46). CXCL1 is maximally effective at $100 \mathrm{ng} / \mathrm{ml}$ in cell culture (47-49). EGF (100 ng/ml, E4127, Sigma-Aldrich) was used as a positive control as reported previously (50). Each experiment was performed independently at least 3 times. 


\section{Western blotting}

Whole-cell extracts from HPDE cells were prepared using RIPA lysis buffer with protease inhibitor cocktail (Sigma-Aldrich) followed by sonication for 5 seconds. Then, protein concentration was determined using the DC protein assay kit (Bio-Rad). Proteins (30-35 $\mu \mathrm{g} / \mathrm{lane}$ ) were separated by SDS-PAGE in $4 \%-20 \%$ NuPAGE Novex Bis-Tris gels and then transferred onto polyvinylidene fluoride membranes. After blocking with $5 \%$ milk in TBST for 1 hour, membranes were probed overnight at $4^{\circ} \mathrm{C}$ with the following primary antibodies: anti-CXCR2 polyclonal rabbit (1:1,000, Abcam, ab65968); anti-CXCR3 polyclonal goat (1:500, Antibodies-online.com, ABIN334381); polyclonal phospho-p44/42 MAPK (Erk1/2) (Thr202/Tyr204) (Cell Signaling Technology, 9101); and GAPDH monoclonal rabbit (1:1,000, Cell Signaling Technology, 2118 , clone 14C10). Horseradish peroxidase-conjugated secondary antibodies (1:3,000, Invitrogen) were applied to the membranes for 1 hour at room temperature. Proteins were visualized using enhanced chemiluminescence (Bio-Rad), and protein expression levels were quantified using the Labworks software (UVP)

\section{Statistics}

Statistical analysis was performed using the 1-tailed Student's $t$ test (for human tissue analysis) or the 2-tailed Student's $t$ test (for rat data and in vitro experiments), or 1-way ANOVA with Dunnett's post-hoc test as indicated in figure legends (Statistica, version 6, Statsoft; GraphPad Prism 5). Data in graphs and tables are presented as means \pm SEM. Findings were assumed statistically significant at $P$ less than 0.05 .

\section{Study approval}

The present studies in humans were reviewed and approved by the University of Florida IRB, Gainesville, Florida, USA, and the UCLA IRB. Informed consent was not required as the human subjects were braindead organ donors. The rodent studies were reviewed and approved by the IACUC at UCLA.

\section{Author contributions}

BS performed the studies and assisted in study design and interpretation and writing the manuscript. ASMM and CM performed the studies and assisted in study design and interpretation. TG and PCB contributed to the study design, study interpretation, and preparation of the manuscript. AM, DK, and SMD assisted in performing studies and study interpretation. DD assisted in evaluating the histology, interpreting the study findings, and in preparation of the manuscript. AEB contributed to study design, evaluating the histology, interpreting the study findings, and in preparation of the manuscript.

\section{Acknowledgments}

We appreciate the technical assistance of Bonnie Yeh and Rosibel Hernandez and the editorial assistance of Bonnie Lui, all from the Hillblom Islet Research Center at UCLA. We appreciate the services of the Translational Pathology Core Laboratory (TPCL) at UCLA for whole-slide scanning. This research was performed with the support of the nPOD, a collaborative T1D research project sponsored by the Juvenile Diabetes Research Foundation International. Organ Procurement Organizations (OPO) partnering with nPOD to provide research resources are listed at www.jdrfnpod.org/our-partners.php. These studies were funded by the NIH/NIDDK (DK077967), the Larry Hillblom Foundation (2014-D-001-NET), and the Juvenile Diabetes Research Foundation.

Address correspondence to: Peter C. Butler, UCLA David Geffen School of Medicine, 900 Veteran Avenue, 24-130 Warren Hall, Los Angeles, California 90095-7073, USA. Phone: 310.794.7645; Email: pbutler@mednet.ucla.edu.

1. Wideroff L, et al. Cancer incidence in a population-based cohort of patients hospitalized with diabetes mellitus in Denmark. J Natl Cancer Inst. 1997;89(18):1360-1365.

2. Huxley R, Ansary-Moghaddam A, Berrington de González A, Barzi F, Woodward M. Type-II diabetes and pancreatic cancer: a meta-analysis of 36 studies. Br J Cancer. 2005;92(11):2076-2083.

3. Cui Y, Andersen DK. Diabetes and pancreatic cancer. Endocr Relat Cancer. 2012;19(5):F9-F26.

4. Li D, Tang H, Hassan MM, Holly EA, Bracci PM, Silverman DT. Diabetes and risk of pancreatic cancer: a pooled analysis of three large case-control studies. Cancer Causes Control. 2011;22(2):189-197.

5. Moreau JA, Zinsmeister AR, Melton LJ, DiMagno EP. Gallstone pancreatitis and the effect of cholecystectomy: a populationbased cohort study. Mayo Clin Proc. 1988;63(5):466-473. 
6. Venkatesh PG, Navaneethan U, Vege SS. Intraductal papillary mucinous neoplasm and acute pancreatitis. J Clin Gastroenterol. 2011;45(9):755-758.

7. Butler AE, Galasso R, Matveyenko A, Rizza RA, Dry S, Butler PC. Pancreatic duct replication is increased with obesity and type 2 diabetes in humans. Diabetologia. 2010;53(1):21-26.

8. Strobel O, et al. Pancreatic duct glands are distinct ductal compartments that react to chronic injury and mediate Shh-induced metaplasia. Gastroenterology. 2010;138(3):1166-1177.

9. Yamaguchi J, et al. Pancreatic duct glands (PDGs) are a progenitor compartment responsible for pancreatic ductal epithelial repair. Stem Cell Res. 2015;15(1):190-202.

10. Butler AE, Janson J, Bonner-Weir S, Ritzel R, Rizza RA, Butler PC. Beta-cell deficit and increased beta-cell apoptosis in humans with type 2 diabetes. Diabetes. 2003;52(1):102-110.

11. Fitzgerald RH, Brewer NS, Dahlin DC. Squamous-cell carcinoma complicating chronic osteomyelitis. J Bone Joint Surg Am. 1976;58(8):1146-1148

12. Zozuliñska D, Majchrzak A, Sobieska M, Wiktorowicz K, Wierusz-Wysocka B. Serum interleukin-8 level is increased in diabetic patients. Diabetologia. 1999;42(1):117-118.

13. Xu H, et al. [Elevated plasma concentration of IP-10 in patients with type 2 diabetes mellitus]. Nihon Jinzo Gakkai Shi. 2005;47(5):524-530

14. O'Neill CM, et al. Circulating levels of IL-1B+IL-6 cause ER stress and dysfunction in islets from prediabetic male mice. Endocrinology. 2013;154(9):3077-3088.

15. Nunemaker CS, Chung HG, Verrilli GM, Corbin KL, Upadhye A, Sharma PR. Increased serum CXCL1 and CXCL5 are linked to obesity, hyperglycemia, and impaired islet function. J Endocrinol. 2014;222(2):267-276.

16. Li D. Diabetes and pancreatic cancer. Mol Carcinog. 2012;51(1):64-74.

17. Matveyenko AV, Butler PC. Beta-cell deficit due to increased apoptosis in the human islet amyloid polypeptide transgenic (HIP) rat recapitulates the metabolic defects present in type 2 diabetes. Diabetes. 2006;55(7):2106-2114.

18. Gurlo T, et al. Evidence for proteotoxicity in beta cells in type 2 diabetes: toxic islet amyloid polypeptide oligomers form intracellularly in the secretory pathway. Am J Pathol. 2010;176(2):861-869.

19. Yang YX. Do diabetes drugs modify the risk of pancreatic cancer? Gastroenterology. 2009;137(2):412-415.

20. Smith U, Gale EA. Does diabetes therapy influence the risk of cancer? Diabetologia. 2009;52(9):1699-1708.

21. Elashoff M, Matveyenko AV, Gier B, Elashoff R, Butler PC. Pancreatitis, pancreatic, and thyroid cancer with glucagon-like peptide-1-based therapies. Gastroenterology. 2011;141(1):150-156.

22. Matveyenko AV, et al. Beneficial endocrine but adverse exocrine effects of sitagliptin in the human islet amyloid polypeptide transgenic rat model of type 2 diabetes: interactions with metformin. Diabetes. 2009;58(7):1604-1615.

23. Singh S, Chang HY, Richards TM, Weiner JP, Clark JM, Segal JB. Glucagonlike peptide 1-based therapies and risk of hospitalization for acute pancreatitis in type 2 diabetes mellitus: a population-based matched case-control study. JAMA Intern Med. 2013;173(7):534-539.

24. Egan AG, et al. Pancreatic safety of incretin-based drugs--FDA and EMA assessment. N Engl J Med. 2014;370(9):794-797.

25. Gier B, Matveyenko AV, Kirakossian D, Dawson D, Dry SM, Butler PC. Chronic GLP-1 receptor activation by exendin-4 induces expansion of pancreatic duct glands in rats and accelerates formation of dysplastic lesions and chronic pancreatitis in the Kras(G12D) mouse model. Diabetes. 2012;61(5):1250-1262.

26. In't Veld P, et al. Beta-cell replication is increased in donor organs from young patients after prolonged life support. Diabetes. 2010;59(7):1702-1708

27. Sullivan BA, Hollister-Lock J, Bonner-Weir S, Weir GC. Reduced Ki67 staining in the postmortem state calls into question past conclusions about the lack of turnover of adult human $\beta$-cells. Diabetes. 2015;64(5):1698-1702.

28. Foulis AK, Stewart JA. The pancreas in recent-onset type 1 (insulin-dependent) diabetes mellitus: insulin content of islets, insulitis and associated changes in the exocrine acinar tissue. Diabetologia. 1984;26(6):456-461.

29. Matveyenko AV, Gurlo T, Daval M, Butler AE, Butler PC. Successful versus failed adaptation to high-fat diet-induced insulin resistance: the role of IAPP-induced beta-cell endoplasmic reticulum stress. Diabetes. 2009;58(4):906-916.

30. Atkinson LL, Topp BG, Au J, Vinerian HV, Dhatt N, Finegood DT. Quantification of the relationship between glycemia and beta-cell mass adaptation in vivo. Can J Physiol Pharmacol. 2009;87(8):602-609.

31. Fontés G, et al. Glucolipotoxicity age-dependently impairs beta cell function in rats despite a marked increase in beta cell mass. Diabetologia. 2010;53(11):2369-2379.

32. Ouyang H, et al. Immortal human pancreatic duct epithelial cell lines with near normal genotype and phenotype. Am J Pathol. 2000;157(5):1623-1631.

33. Miyake M, Goodison S, Urquidi V, Gomes Giacoia E, Rosser CJ. Expression of CXCL1 in human endothelial cells induces angiogenesis through the CXCR2 receptor and the ERK1/2 and EGF pathways. Lab Invest. 2013;93(7):768-778.

34. Moin AS, Butler PC, Butler AE. Increased proliferation of the pancreatic duct gland compartment in type 1 diabetes. J Clin Endocrinol Metab. 2017;102(1):200-209.

35. Majumder S, Chari ST, Ahlquist DA. Molecular detection of pancreatic neoplasia: Current status and future promise. World $J$ Gastroenterol. 2015;21(40):11387-11395.

36. Roy N, Hebrok M. Regulation of cellular identity in cancer. Dev Cell. 2015;35(6):674-684.

37. Pellettieri J, Fitzgerald P, Watanabe S, Mancuso J, Green DR, Sánchez Alvarado A. Cell death and tissue remodeling in planarian regeneration. Dev Biol. 2010;338(1):76-85.

38. Shenoy AK, et al. Transition from colitis to cancer: high Wnt activity sustains the tumor-initiating potential of colon cancer stem cell precursors. Cancer Res. 2012;72(19):5091-5100.

39. Haataja L, Gurlo T, Huang CJ, Butler PC. Islet amyloid in type 2 diabetes, and the toxic oligomer hypothesis. Endocr Rev. 2008;29(3):303-316.

40. Marchetti P, et al. Pancreatic islets from type 2 diabetic patients have functional defects and increased apoptosis that are ameliorated by metformin. J Clin Endocrinol Metab. 2004;89(11):5535-5541.

41. Butler AE, Jang J, Gurlo T, Carty MD, Soeller WC, Butler PC. Diabetes due to a progressive defect in beta-cell mass in rats 
transgenic for human islet amyloid polypeptide (HIP rat): a new model for type 2 diabetes. Diabetes. 2004;53(6):1509-1516.

42. Matveyenko AV, Veldhuis JD, Butler PC. Adaptations in pulsatile insulin secretion, hepatic insulin clearance, and beta-cell mass to age-related insulin resistance in rats. Am J Physiol Endocrinol Metab. 2008;295(4):E832-E841.

43. Campbell-Thompson ML, et al. Collection protocol for human pancreas. J Vis Exp. 2012(63):e4039.

44. Daval M, et al. The effect of curcumin on human islet amyloid polypeptide misfolding and toxicity. Amyloid. 2010;17(3-4):118-128.

45. Schulthess FT, et al. CXCL10 impairs beta cell function and viability in diabetes through TLR4 signaling. Cell Metab. 2009;9(2):125-139.

46. Takahashi K, et al. Serum CXCL1 concentrations are elevated in type 1 diabetes mellitus, possibly reflecting activity of anti-islet autoimmune activity. Diabetes Metab Res Rev. 2011;27(8):830-833.

47. Vasquez RE, Xin L, Soong L. Effects of CXCL10 on dendritic cell and CD4 ${ }^{+}$T-cell functions during Leishmania amazonensis infection. Infect Immun. 2008;76(1):161-169.

48. Sui Y, et al. Neuronal apoptosis is mediated by CXCL10 overexpression in simian human immunodeficiency virus encephalitis. Am J Pathol. 2004;164(5):1557-1566.

49. Kawada K, et al. Chemokine receptor CXCR3 promotes colon cancer metastasis to lymph nodes. Oncogene. 2007;26(32):4679-4688.

50. Niu J, et al. Keratinocyte growth factor/fibroblast growth factor-7-regulated cell migration and invasion through activation of NF-kappaB transcription factors. J Biol Chem. 2007;282(9):6001-6011. 